\title{
Innovative HR Strategies for SMEs
}

\author{
Krishna Kishore, Mousumi Majumdar, Vasanth Kiran \\ Vanguard Business School, Bangalore
}

\begin{abstract}
The Small and Medium Scale Enterprises being very volatile in nature take high amount of risk. It is therefore imperative for them to address the uncertainty through reliable and loyal work force which can shoulder them in good and bad times. HR has the challenge of attracting talent on role dimension and then retaining that talent by providing a professionally driven organization culture. Due to low degree of bureaucracy and leaner work force structure, it is easier for HR to implement change management programs in SMEs. The HR faces the challenge to adhere to the agreed policy norms which succumb to exemption from the owners. HR also needs to understand that the owners do not want to feel themselves devoid of decision making power due to change in policies. HR professionals need to be conscious that professionalism without the loss of agility and responsiveness is the right transformation direction for SME's success. This paper analyses the various innovative HR strategies that can lead to change management and as such ensure a sustainable future for the SMEs.
\end{abstract}

Key words: SME, HR, Strategy, Developing countries, Innovation, Organization citizen behavior

\section{Introduction}

Small and Medium Enterprises (SMEs) are showing their impact on national and regional economies throughout the world. They have been recognized in both developed and developing countries as an effective instrument for creating employment opportunities with a small amount of capital investment.

Small-scale industrial sector plays a dominant role in the economic development of both developed and developing countries. In developing countries cottage and small-scale industries are especially important in context of employment opportunities, equitable distribution of national income, balanced regional growth and development of rural and semi urban areas, Rahman (2006). They provide immediate large-scale employment, offer a method of ensuring a more equitable distribution of the national income and facilitate effective mobilization of resources of capital and skill which might otherwise remain unutilized (ICSI Herald, 1998). Small-scale industries play a very vital role even in industrialized and advanced countries like the U.S.A., the U.K., Canada, and West Germany and more particularly in Japan, Baruha (2000). This sector is considered to be an engine of growth, especially in a developing country like India due to their contribution to income generation, employment, GDP and export earnings. The Indian economy is now the second fastest growing economy of the world. As per the Ministry of Finance, the GDP of India stood at $8.8 \%$ in the first quarter of 2010-11 (the overall growth of GDP in 2009-10 was 7.2\%); overall growth in the Index of Industrial Production (IIP) was recorded at $13.8 \%$ during July 2010 as opposed to $7.2 \%$ in July 2009.

In such a visible growth environment, tremendous efforts are being made by SMEs to make their prominent presence felt and to convert their growth plans into reality. In last two decades, there have been certain spaces where many SMEs have not grown either by choice or by challenges in capabilities to transform their business. SMEs compete with big players either as B2B or as B2C business models. For large businesses, forming strategic alliances and collaborative partnerships can be critical to their ability to seize technological opportunities, to build critical resource strengths and competitive capabilities, to improve supply chain efficiencies and deliver value to their customers (Kaplan and Hurd, 2002).

Since the developing economies are characterised by high unemployment rates, the closure of big businesses, declining economic growth and declined standards of living, it becomes important to promote SMEs as they are a vehicle for employment creation and economic growth. An environment conducive for the growth of SMEs is required, and this has necessitated an investigation into the factors affecting the performance of SMEs.

SMEs are in general labor intensive production units. But surprisingly, HR strategy of small scale manufacturing units is one of the least researched areas (Mankelow, 2008). Whenever we think about an HR manager we think about large firms. Small firms also need HR managers. Performance and effective human resource management enables the entrepreneurs to improve the quality of their production. Hence, the strong business strategies become inevitable for SME sector. The business function in SMEs is hindered by constraints such as limited access to resources, and a lack of expertise on the part of the owner/manager. While entrepreneurs are willing to explore ways to minimize this inertia, HR and its different facets also play an important role to address the growth issues that SMEs face. 
The purpose of this paper is to explore and analyze the SMEs innovative strategic human resource management practices to gain a competitive position in the industry. A focus on intellectual capital, human capital, social capital, core competencies and capabilities is becoming increasingly recognized as a critical success factors for business (Pfeffer, 1998). While research on the HR practices of SMEs has made broad strides (Heneman et al 2000, Leug 2003, Hayton 2003), no research has been focused on the context of how the HR practices of SMEs lead to sustainability. This paper speaks about how HR manager can be effective in SMEs and how innovatively they can manage their labour issues in the turbulent times.

\section{Specific Characteristics of SME Culture}

Small and medium enterprises (SMEs) face unique challenges in managing HR that stem largely from their size (Greening et.al 1996). While economies of scale permit larger organizations to employ a team of specialists to address the complexities involved in managing HR programs, this is not a viable option for many SMEs. The costs associated with hiring highly trained HR professionals on a full-time basis are likely to be prohibitive for many smaller organizations (Arthur, 1995). As a result, HR activities often become the responsibility of general managers (Longenecker, Moore, \& Petty, 1994).

Small businesses have a greater likelihood of coincidence of power between owners and managers. Small business owners usually have direct impact on operations and activities of businesses than owners of large businesses (Cooper 1982; Cressy 1996; Wiklund 1998a, 1998b; Jenkins 2004). A direct role of SME entrepreneur imply multidimensional goals; a commercial orientation as well as personal preferences, objectives and ambitions such as desire for lifestyle, family and reputation in communities (O'Farrell and Hitchens 1988; Birley and Westhead 1994; Spence and Rutherfoord 2001; Southwell 2004). The basic values that SMEs reflect are trust, cost consciousness, agility, high level of risk taking ability, centralized decision making, culture of driving business by intuition and relationships rather than facts and professionalism. Within an ambiance of business diversity, small businesses exhibit a general characteristic of informality which is illustrated by a lack of written management procedures and practices, such as human resource management (Kotey and Slade, 2005). More often than not, the values of the promoter or owner of small businesses are the expected values or culture of the organization. Consequently, the owners play a more critical role in the development of their business than owners of larger businesses (Shuman and Seeger 1986; O'Farrell and Hitchens 1988; Wiklund 1998a, 1998b), prompting Storey (1994, p. 10) to argue a small business is 'not simply a scaled down version of a large firm'. And this perhaps is one of the most important aspects restricting the growth of SMEs as there is a dire need for change in the organization culture to match the challenges of business. The process of decision making in the small business organization acts as a grid lock in the high growth rate of SMEs. Another cultural impediment faced by SMEs is that the existing employees who are well adjusted to the conventional culture generally develop differences with the employees who are recruited from professionally driven big companies.

Human resource is a vital factor that could affect the performance of organization Pfeffer (1998). Therefore, it is important to understand how to manage human resources so as to maximize productivity and enhance creativity as well as control the costs (Combs, Liu, Hall, \& Ketchen, 2006; Dart, Ng, \& Sarkar, 1990). HR strategies give valuable foundations to the rising number of diversified SMEs, (Sethakaset \& Santimataneedol, 2008).

The SME sector as a whole is basically promoter driven. The problem of SMEs is that the promoter reflects values which are different from the values that the employee groups reflect and this difference becomes critical in the business growth process. This is where there is a need for the decision makers to understand about the need for change. Thus the stake of HR becomes very high because of its two-fold role:

i. to continuously influence the promoter/owner on the need for organization culture change ii. to manage the agenda for organization culture change.

$\mathrm{HR}$ also faces the challenge of attracting talent on role, and then retaining that talent by providing a professionally driven organization culture. SMEs are at a disadvantage in their ability to offer competitive packages, which directly acts as a hindrance to the attraction and retention of the talent pool.

\section{Innovative HR Strategies:}

SMEs face unique challenges that stem largely from their size. While economies of scale permit larger organizations to employ a team of specialists to address the complexities involved in managing HR programs, this is not a viable option for many SMEs. However, there has been little to no attention paid to the role the strategic human resource management practices of SMEs in bringing about the sustainability of the business. The uniqueness of the SMEs forces the HR managers to be creative and make some major amendments in their policies. Most of the SMEs failed to achieve their individual objectives due to the lack of human resources and organization capabilities (Chee, 1986; Hashim and Oman, 2003). Other reasons were probably because there was little invention, lack of skilled or know-how workers, traditional methods of operation, cashflow and difficulties in obtaining financial support from financial institutions or the government, lack of human resources development, high level of international competition; lack of willingness to spend on technology facilities, lack 
of skills and knowledge, dependency on the domestic market (Saleh \& Ndubisi, 2006); difficulty in recruiting employees (Williamson, Cable \& Aldrich, 2002) and difficulty in developing sustainable human resource systems and policies (Barber et al., 1999; Cardon \& Stevens, 2004).

The SMEs as their fundamental policy will like to reduce on the training and development expenses. So the role of HR professional increases as the company is not providing the training and development program, he/she needs to recruit the professionals with varied talents preferably persons who can do multitasking. But it is up to HR specialists to hold their nerve in this 'crisis' situation and perhaps do what we do well in such times look for the positive approach to getting through. Strong leadership is vital in turbulent times and they need to focus on employer values and trust relations and lead with emotional intelligence.

The HR needs to focus mainly on the redundancy and the recruitment of employees for the SMEs. In this tough economic environment of competition, it becomes vital for HR Managers to set clear goals and expectations for their employees; and provide them with appropriate feedback. Hence, there is a need for employee involvement and a creative appraisal system to be introduced by the HR department.

Some of the innovative HR strategies to tackle turbulent situations very specific to the SME's are mentioned below:

\subsection{Knowledge Management:}

Knowledge Management (KM) can be comprehensively defined as "an emerging set of organizational design and operational principles, processes, organizational structures, applications and technologies that helps knowledge workers dramatically leverage their creativity and ability to deliver business value', (Gurteen, 1998). Nowadays, Knowledge Management is rapidly becoming an integral business activity for organisations as they realise that competitiveness pivots around the effective management of knowledge (Grover and Davenport, 2001). A systematic approach towards knowledge management adoption in small and medium enterprises (SMEs) sector is very menial.

The important three factors that SMEs should practice are

i. senior management support and leadership,

ii. a knowledge-friendly and sharing culture

iii. a clear strategy for managing knowledge

Appending the above list, the following factors plays an under laying role in success factor for SME's as well (Wong and Aspinwall, 2005).

a. Development of a technological infrastructure,

b. Incentives to encourage Knowledge Management practices

c. Measuring the effectiveness of Knowledge Management

Successful KM in SME's requires positive entrepreneurial support and leadership from promoter/owner and can be implemented through a balanced strategy. Leaders should involve themselves in emphasizing co-operation and knowledge sharing across the organization. They should also contribute to the creation of an environment in which knowledge creation and cross-boundary learning can flourish. In case of SMEs, enforcement of labour training and development of leadership qualities is essential to improve their skill and productivity.

\subsection{Recruitment:}

In the today's liberalized and globalised economy, the nourishing of any organization depends on the integral growth of employee's. Talent crunch can impact any organization's bottom line and growth. SMEs are struggling to fill talent gap, find skilled workers especially at workmen level and middle level positions. Identifying right candidate for a right job with right skill, and aligning their business for getting the quality cost scale balance right, stands as a huge challenge to any SME's. One more important challenge is to, how they can retain their key talent.

SMEs are less inclined towards adopting modern methods of hiring, which is why candidates have less information about the available job opportunities across the board. Role clarity is a major ingredient of successful recruitment. Often SME's does not invest money in doing clear job analysis and fail to give proper job description. Most of the candidates tend to accept the roles without understanding and asking for any clarity and crib later. SMEs are at a disadvantage in their ability to offer competitive pay packages. SMEs require determining skills gap and employee's needs. SMEs seldom offer a detailed orientation program to new joinees. These are the various challenges in recruitments in case of SME sector and the way ahead can be different innovative approaches towards recruitments.

\section{a. Leveraging Multiple Candidate Resources.}

SMEs should market their talent hunt as they market their products and services. Employer brand makes it all difference in opportunities sector. SME's must get into the role of an efficient marketer; who taps into multiple resources for attracting potential candidates to apply. Organizations need to discover innovative ways 
to present themselves as an employer brand in order to distinguish themselves and for effective talent acquisition.

\section{b. Adopting Social Media for Effective Recruiting.}

Networking is one of the most powerful tools to accelerate and maintain success for any individuals and organizations. Social media offers tremendous hiring opportunities for SMEs to not only build their brand but also search for talent. SMEs must infuse social media into the talent and branding equation. Social media builds awareness in the people in fastest way and attracts potential candidates to apply.

\section{c. $\quad$ Establishing a Presence on Job Portal and online platform.}

Online advertisements have been highly successful in abridging the gap between employers and prospective candidates. It will render an opportunity to SME's to post their openings and to candidates to post their professional profiles. Job portals emphasize strongly on updated, complete and authentic information about both companies and candidates, which makes both the parties confident about each other. They serve as a platform for employers to connect with talent and vice versa.

SMEs must realize the importance of an effective employee recruitment plan to sustain their leadership and growth and development in today's competitive marketplace. There are no quick ways to accomplish the above set of activities. If SMEs want to hire the best in the most cost effective way, all of the above have to be carried out regularly and thoroughly. SMEs are required to narrow down on the right resource after a thorough consideration of the position that is required to be filled (Monster India, 2012).

\subsection{Retention:}

As mentioned earlier, the major challenge for SME's is to retain their talent pool because of lack of competitive salary. The job of the HR personnel increases when the present employees are leaving the organization at the time of crisis. The HR personnel should try to retain the present employees by following some of the efficient strategies which include, offering a competitive benefits package that fits the employee needs and expectations, using contests and incentives to help keeping workers motivated and feeling rewarded. Creating open communication between employees and management develops trust in the employees. Fostering employee development and getting managers involved in this activity will give employees a visibility of their own career path. The managers need to spend time in coaching employees, helping good performers move to new positions and minimizing poor performance. Conduct 'Retention interviews', in addition to performing 'exit interviews' to learn why employees are leaving, consider asking longer-tenured employees as to what made them to stick to the organization as per The Wall Street Journal (2012). In today's competitive world, SMEs must recruit and select the best talent where they have openings and upgrade talent in areas where it will advantage the business. It is necessary for the SMEs to take a step back and evaluate workforce plans, as well as talent acquisition processes and enabling technology and determine a strategy that works for the organization in the retention process.

\subsection{Motivation:}

The motivation of employees is one of the key factors that affect the progress of an industry. In SMEs the lack of employees' motivation is a major management deficiency. Keeping employees satisfied on the job is another important human resource activity in the SME's. As financial benefits are not competitive as those of larger and more established firms, the human resource manager of the small firm needs to ensure that its employees remain satisfied on the job. For SMEs the heart of the motivation process lies in ensuring and maintaining smooth and harmonious working and personal relationships among its employees. Respectful language at work place provides support and encouragement and enables employees to develop good working relationships. Mentoring adds up in the strengthening of harmony in the SME.

Effective co-operation and harmony in the workplace ensures less conflict and stress at work. This also leads to higher work motivation, improves labour productivity and in turn ensures higher retention rate. Motivating the employees, specifically for the small firms is to reduce the rates of absenteeism and staff turnover. High levels of absenteeism and turnover adversely impact on the productivity given the number of employees in the small firm and the high cost of recruiting and replacing exiting employees (SME.com, 2012)

The HR should motivate the employees by communicating with them about the benefits offered by the SME. He should also highlight the various opportunities of personal growth, job growth by the organization that can motivate the employee to reach greater heights of productivity within the limited time period. Thus through motivation, the HR professional could improve the efficiency and the effectiveness with which the employees work. Alongside the HR policy should in particular focus on employees' innovation through managing, 
motivating and rewarding the employees at the right time to enhance the competitive advantage (Gupta and Singhal 1993).

\subsection{Job security:}

Any employee prefers to do a job which is secure for him. The SME's should always try to provide the job security for the employees so as to reduce the retention rates. Employees always want to have a 'Secured Job'. Here is how the HR department can add value and definitely make people love the job they do with a psychological satisfaction. The strategies in which HR can create the 'Best Job' are as follows:

a. HR Manager can create an environment which gives the employees an opportunity to give their 100 percent.

b. Think of ways which makes the job more exciting.

c. The HR Manager must recognize the employee's true passions - concepts like knowledge or technology, job functions or skills.

d. HR must make a record of tasks where an employee did something best at the workplace.

e. HR Manager must make a note of the projects where the employee really enjoyed.

f. List down all the accomplishments of the employee and create a mentoring program where employees can talk to people whose advise they value, people who have worked with them, and who have watched them in action.

g. Finally, if an employee is already doing something he/she loves, HR Manager should make it rewarding by aligning them to the goals of the organization, contributing more than what is expected, and giving them every opportunity to learn.

\subsection{Empowerment:}

Empowered employees feel they have the ability to make decisions and put them into action. Empowered personnel are expected to act, at least in some small way, like owners of the company rather than just employees. One of the major tasks faced by HR personnel's is empowering the employees with certain decision making powers and authority. Every employee feels that he should have certain decision making powers with him to do a particular job. The empowerment of employees can happen when the clear definition of the values and mission of the company is explained and imbibed in them. Secondly, company must help employees in acquiring the relevant skills. Thirdly, employees must be supported in their decision-making, and not criticized or do the constructive criticism, when they try to do something extraordinary. And lastly workers need to be recognized for their efforts. Managers have to understand that empowerment is an important strategic tool. In order to reap the benefits, managers should implement the above practices. Otherwise, talk about empowerment will be perceived as "lip service" by employees, and have no positive effect (HelpSME.com, n.d)

\subsection{Employee Engagement:}

Small and medium enterprises (SMEs) are worst affected during challenging economic era when resources are scarce, competition is intense and customers are more demanding than ever. Thus for SMEs it is even important to have emotionally engaged and passionate employees. They play a critical role in driving innovation and propelling the organization forward. Emotionally engaged employees are generally more willing to recommend the organization to others and commit time and effort to help the organization succeed (Gupta, 2009) In SME sector, to build a great workplace and increase employee engagement, there are a few innovative practices which can be adopted to leverage the advantage of the companies as explained in the figure below (Caccamese, 2012).

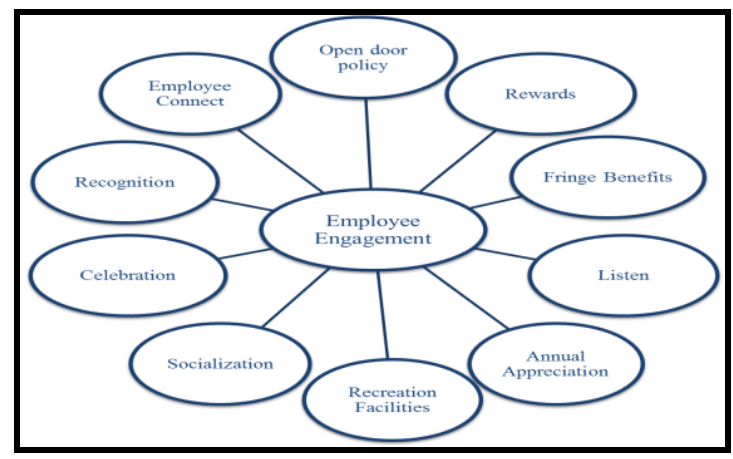

Embracing employee engagement is crucial for SMEs because given the tight financial situation in most of these units, it is more essential for the entrepreneurs to get the work done on time within the firm's budgets. 


\subsection{Workforce diversity:}

In the highly globalized era, the more interaction among people from diverse cultures, beliefs, and backgrounds than ever before is required. People no longer live and work in an insular marketplace; they are now part of a worldwide economy with competition coming from nearly every continent (Byrne, 2011). Cultural diversity training programs must also be set for all the employees and managers or supervisors concerned. This training will help them be aware of the different cultures and beliefs for a diverse workforce existing in company. In a like manner, a seminar or workshop on team building should be frequently conducted and implemented for cohesiveness and unity amidst the diversity of the work. The HR personnel should educate his employees the benefits they will get by working with diverse work force.

\subsection{Organization Citizenship Behaviour:}

As defined by Organ (1988), Organization Citizenship Behavior represents 'individual behavior that is discretionary, not directly or explicitly recognized by the formal reward system, and that in the aggregate promotes the effective functioning of the organization'. It refers to employee efforts that go 'above and beyond the call of duty' (Bolino and Turnley, 2003). Organizational citizenship behavior makes a difference in organizational outcomes (Organ, 1997). Specifically in every SME, the number of work force is very limited. So there is a desperate need of every employee to have and show the belongingness towards the organization. This ensures the organizations to sustain in the today's competitive world. According to the studies of Organ (1988) and Podsakoff et al. (1990; 2000), organizational citizenship behavior consists of five categories listed below, which needs to be fostered innovatively by the HR managers of SME's.

\subsubsection{Conscientiousness:}

Conscientiousness is defined as behaviors on the part of the employee that go well beyond the minimum role requirements of the organization, in the areas of attendance, obeying rules and regulations and taking breaks' (Podsakoff et al, 1990). Diligent employees will increase performance levels and they will be willing to work above their average results (Podsakoff et al., 2000). As one of the strategy of HR, employees have to be brought in to the culture of conscientious, which increases the productivity by itself. These employees do not need much supervision which provides extra time for the supervisor to handle his other tasks (Podsakoff et al., 2000). The working environment in SME is informal and there exist less communication. Thus SME need to recognize and value the employees who are hardworking and trustworthy to follow organizational policies even when they are not monitored.

\subsubsection{Sportsmanship:}

Sportsmanship is defined as the willingness of employees to tolerate less than ideal circumstances without complaining' (Podsakoff et al., 1990). This attitude among the SME employees can enable smooth operation without many hitches of complaints with regards to unimportant matters and focus on what went well instead of what went wrong. This saves time for more productive purposes. Sportsmanship behavior of employees set an example for others which will reduce complaining, increase satisfaction and enhance employee retention (Podsakoff et al., 2000). Within a small organisation, complaining and spreading complaints throughout the workforce diminishes the morale. Sportsmanship behavior is therefore very important for maintaining the valued team spirit.

\subsubsection{Courtesy:}

Courtesy is defined as 'discretionary behavior on the part of an individual, which involves helping others by minimizing work-related problems to occur' (Podsakoff et al., 1990). Behaving courteously will allow employees to gel well among themselves which in turn prevent conflicts. This will decrease the amount of time and energy spent by the supervisor in negotiating conflicts which otherwise would have occurred. Within SMEs, in order to maintain productivity with the small workforce, it is of special importance that employees help their leaders by preventing problems from occurring (Podsakoff, 2000). Courteous behavior enhances organization's ability to quickly adapt to environmental changes, thus having a positive impact on the organizational performance (Podsakoff, 2000).

\subsubsection{Altruism:}

Altruism is defined as 'all discretionary behavior that has the effect of helping others with an organizationally relevant task and/or problem' (Podsakoff et al., 1990). Especially in SME's with a limited workforce and a 'learning-on-the-job' environment, it is important that employees help each other out. This behavior invokes a collaborative working environment leading to enhanced team spirit, strong personal relations, improved feeling of belongingness and thus resulting in higher productivity. The practice of this culture in SME's plays a vital aspect in any organization. Employees like working for the organization; a 
friendly atmosphere makes the organization more attractive to work for and it is therefore less likely that employees will leave the organization (Podsakoff et al., 2000).

\subsubsection{Civic Virtue:}

Civic virtue is defined as 'behavior of the employee that implies the responsible participation in the political life of the organization, like attending meetings and reading the intramural mail' (Podsakoff et al., 1990). Civic virtue is not taken into consideration in this research, because previous research only showed a weak correlation with leadership behavior (Podsakoff et al., 1996).

\section{Conclusion:}

SMEs put extra pressure on HR professionals to prove the merit of its programs and activities for the success of the organization. There are many opportunities to recreate the role and deliver new value to the employees. SMEs must understand the difference between the traditional and the conventional approach of Talent Attraction to execute the much required change for effective hiring. SMEs largely require focusing on recruiting individuals with the appropriate skills, using suitable evaluation procedures that verify the candidate's expertise. HR professionals are challenged with the difficult task of understanding the employees in leading and empowering the employees. While some argue that the financial conditions of SMEs are difficult and ambiguous, but it is an opportunity for HR transformation that will successfully lead, impact and endure the employees to perform well and develop the organization.

HR functions deal with different dynamics when contributing to SME growth plan. While the organization plans to follow a successful trajectory, there is a need for both HR and the Promoters to appreciate and agree on change management agenda through change in organization culture. HR has the responsibility to understand business dynamics in SME environment before implementing the standard HR practices, policies and processes. Due to low degree of bureaucracy and leaner work force structure, it is easier for HR to implement change management programs in SMEs. The mutual appreciation will help HR to be an effective business partner.

\section{Reference:}

[1]. Angione, J. (2001). The visionaries. The ProEmp Journal, 5: 28-39.

[2]. Barber, A.E., Wesson, M.J., Roberson, Q.M., \& Taylor, S.A. (1999). A tale of two job markets: Organizational size and its effects on hiring practices and job search behavior. Personnel Psychology, 52, 841-868.

[3]. Baruah, R. K. (2000): Financing Small Scale Industries, Omsons Publications, Delhi.

[4]. Berle, A., and Means, G. (1932), The Modern Corporation and Private Property, New York: Macmillan.

[5]. Birley, S., and Westhead, P. (1994), 'A Taxonomy of Business Start-Up Reasons and their Impact on Firm Growth and Size,' Journal of Business Venturing, 9, 7-31

[6]. Bolton (1971), Report of the Committee of Inquiry on Small Firms (Bolton Committee Report), London: HMSOF

[7]. Bolino, M.C. and Turnley, W.H. (2003), Going the extra mile: cultivating and managing employee citizenship behavior, Academy of Management Executive, vol. 17, no. 3, pp. 60-71

[8]. Byrne, M. (2011), Workplace diversity, retrieved from (http://www.smeadvisor.com/2011/06/management-workplace-diversity/).

[9]. Caccamese, L. (2012), 10 tips for SMEs to increase employee engagement (http://www.greatplacetowork.com/publications-andevents/blogs-and-news/920-sizing-up-small-businesses\#ixzz21pwO4WMH, accessed on 20 July 2012)

[10]. Cardon, M., \& Stevens, C. (2004). Managing human resources in small organizations: What do we know? Human Resource Management Review, 14, 295-323.

[11]. Chee, P.L. (1986). Small Industry in Malaysia. Kuala Lumpur: Berita Publishing Sdn. Bhd

[12]. Combs, J., Liu, Y., Hall, A., \& Ketchen, D. (2006). How much do high-performance work practices matter? A meta-analysis of their effects on organizational performance. Personnel Psychology, 59(501-528).

[13]. Cyert, R., and March, J. (1963), A Behavioral Theory of the Firm, Englewood Cliffs, NJ: Prentice Hall

[14]. Cooper, A.C. (1982), 'The Entrepreneurship -Small Business Interface,' in Encyclopedia of Entrepreneurship, eds. C. Kent, D. Sexton and K. Vesper, Englewood Cliffs, NJ: Prentice Hall

[15]. Cressy, R. (1996), 'Pre-Entrepreneurial Income, Cash-Flow Growth and Survival of Startup Businesses: Model and Tests on UK data,' Small Business Economics, 8, $49-58$.

[16]. Dart, J., Nag, I., \& Sarkar, A. (1990). A comparative analysis of managerial practices among SMEs from Malaysia, Singapore and Thailand. ASEAN Economic Bulletin, 7(1), 84-95.

[17]. Grover, V. and Davenport, T.H. (2001), "General perspectives on knowledge management: fostering a research agenda", Journal of Management Information Systems, Vol. 18 No. 1, pp. 5-21.

[18]. Gurteen, D. (1998), “Knowledge, creativity and innovation’”, Journal of Knowledge Management, Vol. 2 No. 1, pp. 5-13.

[19]. Gupta, S. (2009), Employee engagement key to success for SMEs, (http://www.smetimes.in/smetimes/news/topstories/2009/Jun/24/employee-engagement-key-to-success-for-smes6604.html, accessed on $20^{\text {th }}$ July 2012).

[20]. Gupta, A., \& Singhal, A. (1993). Managing human resources for innovation and creativity. Research Technology Management, 36 (3), 41-48.

[21]. Habbershon, T., Williams, M., and MacMillan, I. (2003), 'A Unified Systems Perspective of Family Firm Performance, 'Journal of Business Venturing, 18, 4, 451-465

[22]. Hashim, M.K. and Osman, I. (2003). An Evaluation of the Business Practices in Malaysian SMEs, Malaysian Management Review, $38(2), 1-8$

[23]. Hayton, J.C. 2003. Strategic Human Capital Management in SMEs: An Empirical Study of Entrepreneurial Performance," Human Resource Management 42(4), 375-391

[24]. HelpSME.com (n.d), (retrieved from http://helpsme.com/articles/managing-people-well/employee-empowerment, accessed on 20 July 2012). 
[25]. Heneman, R.L., J.W. Tansky and S.J. Camp. 2000. "Human Resource Management Practices in Small and Medium Sized Enterprises: Unanswered Questions and Future Research perspectives," Entrepreneurship Theory and Practice 25(1), 11-26.

[26]. ICSI Herald, Vol. IX, No.4, April 1998. p.13.

[27]. Jenkins, H. (2004), 'A Critique of Conventional CSR Theory: An SME Perspective,' Journal of General Management, 29, 4, 37 57

[28]. Kaplan, N.J. and J. Hurd. 2002. "Realizing the Promise of Partnerships," Journal of Business Strategy, 23(3), 38-42

[29]. Katz, D. (1964), The motivational basis of organizational behavior, Behavioral Science, vol. 9, no. 2, pp. 131-146

[30]. Kotey, B., and Slade, P. (2005), 'Formal Human Resource Management Practices in Growing Small Firms,' Journal of Small Business Management, 43, 1, 16-40

[31]. Leug, A. 2003. "Different Ties for Different Needs: Recruitment Practices of Entrepreneurial Firms at Different Developmental Phases, Human Resources Management 42(4), 303-320.

[32]. Mankelow, G. (2008), Social responsibility paradox of small business human resource management practices, The International Journal of Human Resource Management, Vol. 19, No. 12, p 2171-2181

[33]. Monster India (2012), Monster India white paper on 'How Can SMEs Recruit Effectively' (White paper), (Retrieved from, http://www.moneycontrol.com/news_html_files/news_attachment/2012/Whitepaper_How\%20Can\%20SMEs\%20Recruit\%20Effect ively.pdf, Accessesd on $19^{\text {th }}$ July 2012).

[34]. O'Farrell, P.N., and Hitchens, D.M. (1988), 'Alternative Theories of Small-Firm Growth: A Critical Review,' Environment and Planning, 20, 1365- 1383

[35]. Organ, D.W. (1988) Organizational Citizenship Behavior, The Good Soldier Syndrome, School of Business, Indiana University, Lexington Books Massachusetts/Toronto.

[36]. Organ, D.W. (1997), Organizational Citizenship Behavior: It's construct clean-up time, Human Performance, vol. 10, no. 2, pp. 8597.

[37]. Pfeffer, J. (1998). Seven practices of successful organizations. California Management Review, 40(2), 96-124.

[38]. Pfeffer, J. (1998). The Human Equation: Building Profits by Putting People First. Boston, Mass.: Harvard Business School Press.

[39]. Podsakoff, P.M., MacKenzie, S.B., Moorman, R.H., Fetter, R. (1990), Transformational leader behaviors and their effects on followers' trust in leader, satisfaction, and organizational citizenship behaviors, Leadership Quarterly, vol. 1, no. 2, pp. 107-142

[40]. Podsakoff, P.M., MacKenzie, S.B. and Bommer, W.H. (1996), Transformational leader behaviors and substitutes for leadership as determinants of employee satisfaction, commitment, trust and organizational citizenship behaviors, Journal of Management, vol. 22, no. 2, pp. $155-156$, pp. $259-298$

[41]. Podsakoff, P.M., MacKenzie, S.B., Paine, J.B., Bachrach, D.G. (2000), Organizational citizenship behaviors: a critical review of the theoretical and empirical literature and suggestions for future research, Journal of Management, vol. 26, no. 3, pp. 513-563

[42]. Rahman, M. (2006): 'A Study on the Problems and Prospects of Small-Scale Industries in Hill Districts of Assam' (Unpublished Ph.D Thesis), Department of Commerce, Assam University, Silchar. P.1.

[43]. Saleh AS and Ndubisi NO (2006). SME Development in Malaysia: Domestic and Global Challenges, University of Wollongong, Working paper series, wp06-03.

[44]. Sethakaset, P., \& Santimataneedol, T. (2008). The application of Human resource Management in Thai SMEs: A case study of Albatross Company Limited. Malardalen University, Bangkok.

[45]. Shuman, J.C., and Seeger, J.A. (1986), 'The Theory and Practice of Strategic Management in Smaller Rapid Growth Firms, American Journal of Small Business, Summer, 7 - 18.

[46]. SME com (2012)

[47]. Storey, D. (1994), Understanding the Small Business Sector, London: Routledge.

[48]. Southwell, C. (2004), 'Engaging SMEs in Community and Social Issues,' in Responsibility and Capital: The World of Small and Medium Sized Enterprises, eds. L. Spence, A. Habsich and R. Schmidpeter, Basingstoke: Macmillan.

[49]. Spence, L., and Rutherfoord, R. (2001), 'Social Responsibility, Profit Maximisation and the Small Firm Owner-Manager,' Journal of Small Business and Enterprise Development, 8, 2, 126-139.

[50]. The Wall Street journal, (2012), "Employee Retention - How to Retain Employees" (retrieved from http://guides.wsj.com/smallbusiness/hiring-and-managing-employees/how-to-retain-employees/ accessed on $20^{\text {th }}$ July 2012).

[51]. Ulrich, D. (1996). Human resource champions: the next agenda for adding value and delivering results. Boston, MA, Harvard Business Press.

[52]. Wiklund, J. (1998a), Small Firm Growth and Performance: Entrepreneurship and Beyond, Jonkoping University: Jonkoping International Business School.

[53]. Williamson, I.O., Cable, D.M., Aldrich, H.E. (2002). Smaller but not necessarily weaker: How small businesses can overcome barriers to recruitment, Managing People in Entrepreneurial Organizations, 5, 83-106

[54]. Wong, K. Y. and Aspinwall, E. (2005) An empirical study of the important factors for knowledge-management adoption in the SME sector, Journal of Knowledge Management, Vol. 9, No. 3, pp. 64-82, 